\title{
A Safety Transport Model for Validation of UK Coach Operators for School Journeys
}

\author{
Manoharan Ramachandran, Reza Sahandi, Simant Prakoonwit, Wajid Khan and \\ Siti Aishah Mohd Selamat \\ Department of Science and Technology, Bournemouth University, \\ Bournemouth, United Kingdom \\ \{ mramchandran, rsahandi, sprakoonwit, wkhan, aishah\} @bournemouth.ac.uk
}

\begin{abstract}
Coaches are considered to be one of the safest modes of transport for children in the UK. In the last 10 years alone, 1191 children were injured in 371 coach crashes. Though the government has strict regulations to maintain road worthiness of the coaches, operator non-compliance was the major reason for these accidents. In last year alone, 137 coach operator licenses have been revoked due to operator non-compliance in the UK. Currently, there is no process to reliably mitigate the safety risks of children travelling by coaches. This has created a requirement to validate all the coach operators before using their coaches for school trips. This paper proposes a novel safety model for validation of coach operators prior to commencement of coach journeys.
\end{abstract}

Keywords: School transport; school trips; children safety; coach accidents; operator non-compliance; coach hires.

\section{Introduction}

Safety in transport is concerned with the protection of life by regulating, managing and developing technology for all forms of transport. People use transport for day-today activities such as school, work and business movements or for social and leisure purposes. Safety in school transport systems is critical as it involves children, who are the most vulnerable users [1]. Every year, schools in England alone makes more than $48000+$ local journeys [2] and they depend on coach operators for most of their national and international journeys [3]. Coach journeys are considered to be one of the safest modes of transport, in comparison with other modes of transport but, it has a higher percentage of casualties per accident $[4,5]$. According to national accident statistics of Great Britain (GB), between 2005 and 2015, 1191 children were injured in 371 coach crashes [6]. Contributory factors for these accidents were driver errors and technical faults in vehicles caused by operator non-compliance [7]. Even having strict regulations on operator's compliance with government guidelines, in 2016 alone, 137 coach operators' licenses have been revoked in GB due to operator's noncompliance [8]. This indicates that the existing regulations have not been properly implemented by coach operators. This indicates that there is a need for validation of coach operators, drivers and vehicles before they commence any journey. There are 
only limited studies available in the literature that analyse the safety of school transport through coaches in the UK. Also, there is no specific safety model available to improve the safety of children travelling by coaches. In this paper, we propose a novel, safety model for validation by UK coach operators. The model has been developed as a response to government accident statistics [6], traffic commissioner reports [8] and a qualitative survey conducted in the UK. The model collects data relating to vehicles, drivers and coach operators and calculates safety scores based on the operator's compliance to the UK government's safety guidelines. These safety scores are then used to rank coach operators from the most to the least safe. The scores will guide schools in their selection of coach operators. The remainder of this paper is organized as follows. An overview of the existing technologies and relevant models are discussed in Section 2. The analysis of a qualitative survey is presented in Section 3. Significant issues and requirements have been identified which are discussed in the Section 4. Section 5 describes the proposed model and Section 6 provides discussions on its evaluation. Finally, conclusions and future work are outlined in Section 7.

\section{Literature Review}

Recent fatal accidents involving school children in the UK have alarmed safety professionals and the UK government [9-11]. Reducing coach accidents through policy updates [12] has been one of the most important goals of the UK government for a long time, as it involves a high number of fatalities per accident. This concern is even more important in school transport, which is more critical than other types of transport, as it involves school children, who are the most vulnerable users. Recent advances in school transport systems has given birth to intelligent school transport systems (ISTS) which attempts to tackle issues faced in school transport which may be classified in to three major categories; school bus routing, vehicle \& driver monitoring and children monitoring [13]. However, there are limited studies addressing the validation of coach operator compliance [14]. In 2014, revised home to school travel and transport guidance was released by the UK government for local authorities, parents and other interested parties [12]. No criterion for selecting coach operators for school trips was included in the guidance. There are 217 county councils in the UK (England - 152, Scotland - 32, Wales - 22 and Northern Ireland - 11). County councils follow the national transport guidelines for home to school travel. However, some county councils have amended the national guidelines and created an enhanced version [14]. In addition, Northamptonshire county council has compiled a checklist for coach operators, wherein they require the operators to confirm compliance by signing and passing it on to the school's Headmaster before the journey [15]. The checklist helps operators to reiterate whether the coach and driver(s) are fit for purpose. To reduce accidents due to operators' non-safety compliance, and to help the operators to improve their safety levels, the Volvo vehicle manufacturing company has implemented a scientific approach for their coaches and trucks. The system monitors the four main requirements of the Driver and Vehicle Licensing Agency (DVLA) that include road worthiness, traffic enforcement, 
monitoring and safety [16]. Volvo has also implemented real-time on-board fault diagnostic systems, active truck load monitoring systems and Volvo's Dynafleet online on some of the products to keep their coaches safe, legal and in control. The system also includes a service point online to keep the data associated with the Driver Vehicle and Standards Agency (DVSA) compliant. However, there is still a knowledge gap with schools in respect of the operators' safety compliance which can be used prior to booking a coach. There is no specific safety model available to guide and ensure the safety of children travelling in coaches in the UK [13]. Therefore, a novel safety transport model which validates the coach operators and guides the schools to select the safest operator while booking the journey is proposed. The development of the model was guided by the analysis of the coach based school accidents records from the STATS19 database [6], the traffic commissioners' reports [8] and a survey which was conducted utilising relevant authorities, practitioners and users.

\section{The Survey}

A qualitative survey was conducted in Luton Borough Council (in the East of England), which had more coach accidents and operator licenses revoked compared to most of the other regions. The survey was conducted for a period of 6 months, between March 2016 and September 2016. A total of 42 experienced stakeholders (coach operators, coach drivers, parents, school headmasters, road-safety analysts and council transport officers) were selected for in-depth qualitative interviews. The thematic analysis method proposed by Braun and Clark [17, 18] was used to analyse the transcripts. The results showed two major themes, safety issues and requirements of the stakeholders, for coach based school transport as shown in Tables 1 and 2. Section 4 provides detailed discussions on these issues, as well as the actions taken.

Table 1. Top 10 Safety issues identified

\begin{tabular}{ll}
\hline No & Safety Issues \\
\hline 1 & $\begin{array}{l}\text { Unaware of driver and vehicle } \\
\text { condition }\end{array}$ \\
2 & $\begin{array}{l}\text { Children behaviour at (bus stop, } \\
\text { inside bus) }\end{array}$ \\
3 & $\begin{array}{l}\text { Time delays by parents-drivers } \\
\text { (lateness) }\end{array}$ \\
4 & $\begin{array}{l}\text { Inexperienced driver (driver error) } \\
5\end{array}$ \\
6 & $\begin{array}{l}\text { Driver got disturbed by pupils in bus } \\
\text { Vehicle out of control (vehicle error) }\end{array}$ \\
7 & $\quad \begin{array}{l}\text { Driver fatigue } \\
8\end{array}$ \\
9 & $\begin{array}{l}\text { Other vehicles behaviour around the } \\
\text { busternal factors) }\end{array}$
\end{tabular}

Table 2. Top 10 Requirements identified

\begin{tabular}{ll}
\hline No & Requirements \\
\hline 1 & Bus Escorts \\
2 & Vehicle Tracking \\
3 & $\begin{array}{l}\text { Information about driver's and } \\
\text { vehicle's status }\end{array}$ \\
4 & $\begin{array}{l}\text { Supervise students at the bus stops } \\
5\end{array}$ \\
6 & $\begin{array}{l}\text { CCTV cameras } \\
\text { Schools need to check the }\end{array}$ \\
7 & $\begin{array}{l}\text { for safety reasons driver's documents } \\
\text { education }\end{array}$ \\
8 & $\begin{array}{l}\text { Avoid narrow roads and sharp } \\
\text { bends }\end{array}$ \\
9 & Use routes with brighter bus stops
\end{tabular}




\section{Significant issues and requirements}

In an attempt to reduce accidents for children travelling by coaches, the UK government guidelines [12], [22]-[34] were considered. The requirement for coach operators to maintain the safety of their fleet in the UK was also used as an important issue for consideration. The following table shows the importance of the issues and requirements over others.

Table 3. Significant issues and requirements

\begin{tabular}{|c|c|c|}
\hline No. & Issues/Requirements & How the proposed model going to solve it? \\
\hline 1 & Unaware of driver and vehicle condition & $\begin{array}{l}\text { The model will bridge the gap between the stakeholders } \\
\text { by presenting the vehicle and driver safety scores to the } \\
\text { customers (schools/parents) when they try to book a } \\
\text { coach with the coach operator. }\end{array}$ \\
\hline 2 & Inexperienced driver (driver error) & $\begin{array}{l}\text { Safety score for each driver is calculated based on the } \\
\text { driver experience and points on his/her license }+ \text { other } \\
\text { factors (DBS, Health records, Driving hour violations } \\
\text { etc.). So the accidents occurring due to driver error [7] } \\
\text { can be reduced by selecting the right driver. }\end{array}$ \\
\hline 3 & Vehicle out of control (vehicle error) & $\begin{array}{l}\text { Safety score for each vehicle is calculated based on } \\
\text { various vehicle related attributes which includes, vehicle } \\
\text { accident history, daily walk around checks, 6/8/12 } \\
\text { weekly safety checks, yearly MOT, valid Insurance etc. } \\
\text { Accidents occurring due to vehicle error [7] can be } \\
\text { reduced by selecting the right vehicle. }\end{array}$ \\
\hline 4 & Driver Fatigue & $\begin{array}{l}\text { One of the attributes for calculating the driver safety } \\
\text { score is the driver's driving hour violation through the } \\
\text { analysis of Tachograph history. Using the driver who } \\
\text { has low violation in driving hours may possibly reduce } \\
\text { accidents occurring due to driver fatigue [19] caused by } \\
\text { irregular rest. }\end{array}$ \\
\hline 5 & $\begin{array}{l}\text { Information about driver and vehicle } \\
\text { status }\end{array}$ & $\begin{array}{l}\text { Similar to Issue No.1, Parents and Schools requested to } \\
\text { check the driver's and vehicle's status before the } \\
\text { journey to validate them (i.e) to make sure they are safe } \\
\text { for the journey. }\end{array}$ \\
\hline 6 & $\begin{array}{l}\text { Schools need to check the vehicle's and } \\
\text { the driver's documents for safety } \\
\text { reasons }\end{array}$ & $\begin{array}{l}\text { Similar to Issue No.1. Parents requested the schools to } \\
\text { check the driver's and vehicle's documents for a safe } \\
\text { journey. Both, point } 5 \text { and } 6 \text { can be rectified through this } \\
\text { model. }\end{array}$ \\
\hline
\end{tabular}

\section{Cloud Based Coach Journey Validator Model}

Before the model is discussed in detail, it is important to understand how the quotation process works. For the purpose of this paper, quotation is the process for 
obtaining prices from coach operators for a particular school journey between two points. Usually a Headmaster or an event coordinator in a school carries out a safety assessment for a school trip and then selects an appropriate coach operator to provide the service. There are many coach operators in the UK who provide coach services for school trips. To select a coach operator, a Headmaster/event coordinator (users) normally provides details of a school journey to several coach operators (brokers) to obtain quotations. A quotation normally provides a list of vehicles with corresponding prices for the journey. The prices vary depending on the type of coach and number of passengers. If the user is happy with the quotation, a booking is made for the coach. Figure 1 shows the existing quotation process where no validation of coach operators involved.

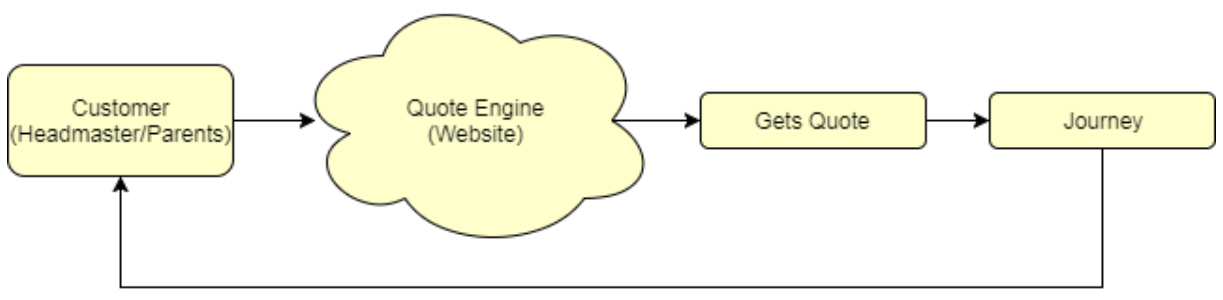

Fig. 1. Existing Quotation Process.

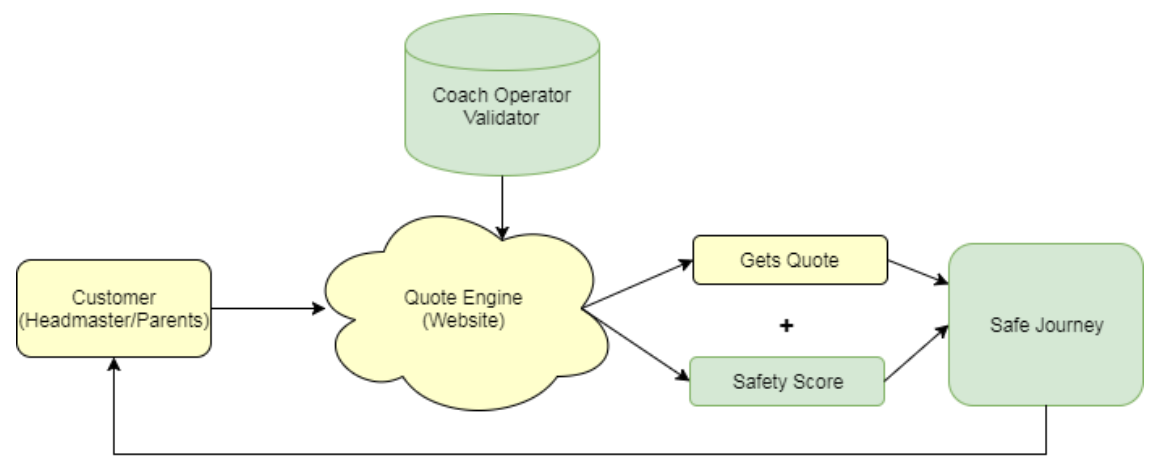

Fig. 2. Proposed Quotation Process.

We propose a model to introduce a coach journey validator that connects with the existing quotation system as shown in Figure 2. The model can also act as a standalone system for validation of a coach operator without the quotation engine. The proposed model consists of 5 steps: data acquisition, data verification, data weight assignment, safety score calculation and quote engine connection. Basically, the model collects a coach operator's data relating to vehicles and drivers and produces a safety score for each journey. Weighting parameters are used, based on the UK 
government's guidelines and regulations for coach operators [22]-[34] to determine the safety level. Figure 3 shows the process decomposition of the model for creation of the journey validator.

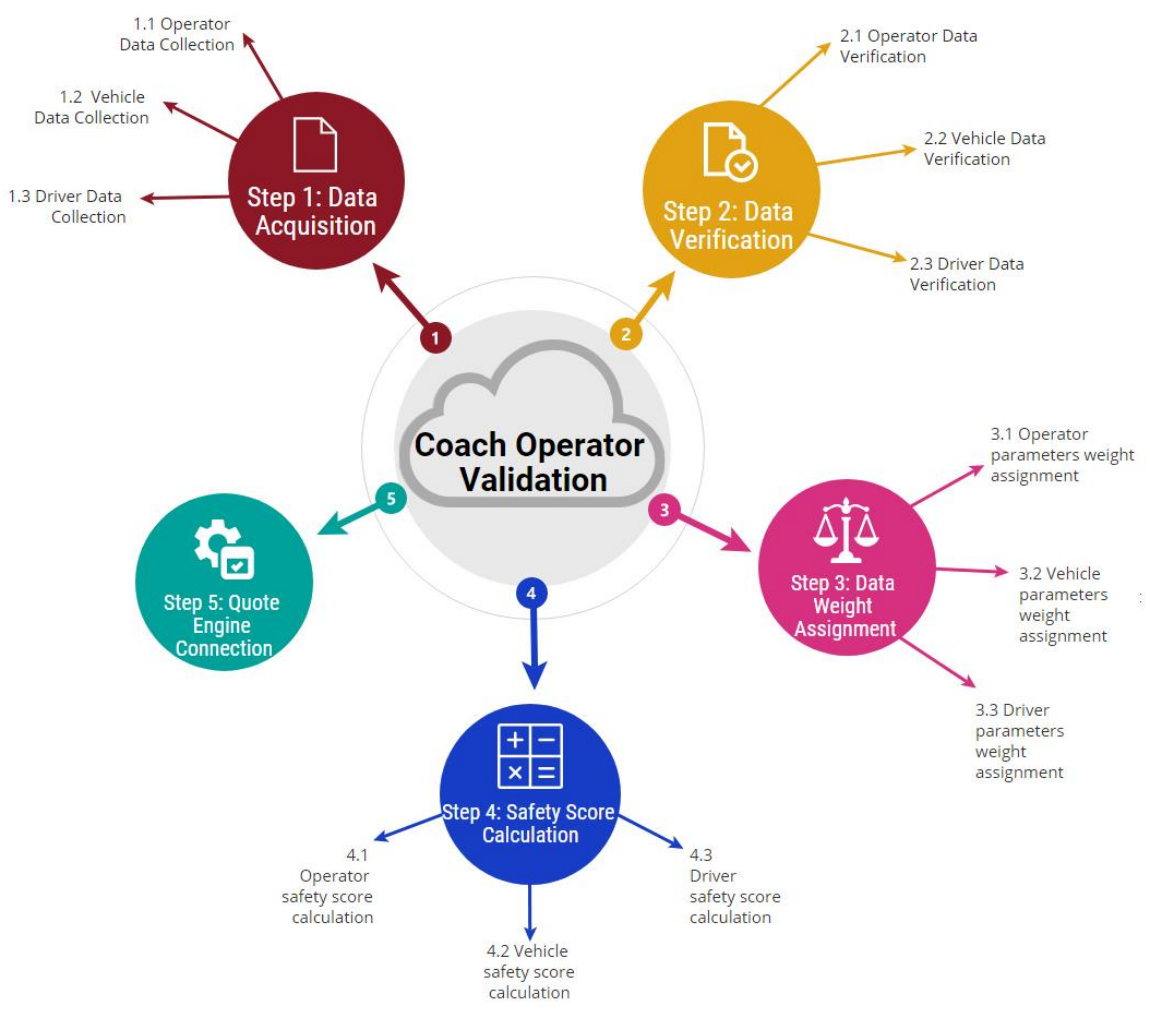

Fig. 3. Coach Operator Validator Model Process Decomposition

Data Acquisition: Coach Operator's data in respect of vehicles and drivers are obtained through a data acquisition process. The key step in this model is the data acquisition phase in which, the attributes and parameters are determined according to the standards set by Driver Vehicle and Standards Agency (DVSA), in addition to following the guidelines for coach operators in the UK [22]-[34]. First, detailed information such as, Traffic Operator Compliance Risk (OCR) scores, Roadworthiness OCR scores, Combined OCR scores, operator license validity etc., are collected. Information about the fleet such as the number of vehicles in the fleet, safety checks, the compulsory tests set by the Ministry of Transport (MOT), insurance validity, vehicle accident history etc., are collected. Data related to drivers working for the operator, including the number of drivers, their experience, points on their licenses, DBS checks, etc. are also collected. 
Data Verification: Subsequent to obtaining the data from the operator, it is verified using authorised government databases. First the operator's data is retrieved from the DVSA database and compared with the information obtained from the operator. If they match, then the operator's data is verified. Similarly, vehicles and drivers' data are retrieved from the operator and compared with the information on the DVLA databases for verification.

Data Weight Assignment: Once the coach operator's data is verified, it is divided into three parts: operator's attributes, vehicle's attributes and driver's attributes. Subsequently, weighting factors are assigned to the attributes using the UK Government's scoring systems to calculate the safety scores data. High risk attributes have higher weighting factor whereas the medium and minimal risk attributes are given lower weighting factors. (Example: OCR score attribute can have a weighting factor distribution of 3 to 1 based on the OCR score i.e., Green -3, Amber -2 and Red $-1)$.

Safety Score Calculation: Once the weighting factors are assigned, individual safety scores for an operator, their vehicles and their drivers are calculated. Details of safety score calculations are discussed in [32]. Quote Engine Connection: Once details of a school trip are provided to the quote engine of a coach operator, a list of vehicles along with their safety scores and quotations for each vehicle are displayed. More details be found in [32].

\section{Testing the Model}

The model was tested in-house and by a number of practitioners. During in-house testing, data was fed into the model to check accuracy of performance. Corrections were made during this initial test and the model was refined further. Real time data was obtained from two coach operators in Luton in the UK who are registered with Luton Borough Council, who also contributed to the testing process and used to test the model. More details may be found in [32]. Feedback received from the coach operators, who were involved during the testing process, was also incorporated within the model.

Results confirmed that the model works well and safety scores calculated for typical journeys were accurate, when compared with scores obtained from authorised UK Government sources. The real-time test has so far confirmed the capability of the model, which may be used for wider applications, possibly globally after some modifications to it.

To further confirm it is fit for purpose and its capability, the model will be evaluated shortly by a larger number of transport companies within the Luton Borough County and across the UK. 


\section{Conclusion and Future Work}

Safety of school transport is a critical issue which should be addressed effectively. Safety in coach-based school transport in GB is a less investigated area compared to other modes of school transport. Coach operator's non-compliance is a major issue in the coach industry. This requires immediate attention before more children lives are put at risk. This paper presents a novel safety transport model for validation of operators/coaches for school journeys in the UK. The results of a qualitative survey conducted for school coach journeys in the UK were presented and significant issues and the requirements were identified and discussed. A model is proposed for validating operators/coaches for school trips prior to their bookings. Testing of the model using real data from two coach operators in Luton confirmed its capability. The model may be deployed for wider applications across the UK to reduce the number of accidents due to operators' non-compliance. By providing safety scores, the model can inform users (schools and parents) of suitable operators, vehicles and drivers for school journeys. The model will be evaluated by the participation of a large number of transport companies within the Luton Borough County and across the UK.

There is potential to expand the model further. Features such as vehicle monitoring and driver monitoring, etc., can be integrated in this model.

\section{References}

1. Kalogirou, K., Chalkia, E., Bekiaris, E., Diederichs, F.: An Application for the Information of Children According their School Transportation. Procedia - Soc. Behav. Sci. 48, 363-372 (2012).

2. Drake, R.: Schools, pupils and their characteristics, https://www.gov.uk/government/statistics/schools-pupils-and-their-characteristicsjanuary-2016.

3. Move, D.G.: Comprehensive Study on Passenger Transport by Coach in Europe. (2016).

4. Albertsson, P., Björnstig, U., Falkmer, T.: The Haddon matrix, a tool for investigating severe bus and coach crashes. Int. J. Disaster Med. 1:2, s. 10, 109-119 (2003).

5. Doohan, I., Saveman, B.I.: Impact on life after a major bus crash - a qualitative study of survivors' experiences. Scand. J. Caring Sci. 28, 155-163 (2014).

6. DfT: Department for Transport (Great Britan) Road Safety Data - Datasets, https://data.gov.uk/dataset/road-accidents-safety-data.

7. DfT: Department for Transport (Great Britan) : Contributory factors for reported road accidents, https://www.gov.uk/government/statistical-data-sets/ras50-contributoryfactors.

8. Commissioners, T.: Traffic Commissioners' Annual Reports, https://www.gov.uk/government/collections/traffic-commissioners-annual-reports.

9. Bishop, R., Campbell, S.: France coach crash: Two British school kids critically injured and 13 hurt in motorway accident, http://www.mirror.co.uk/news/worldnews/france-coach-crash-two-british-8477595, (2016).

10. Fox, A., Bumett, R.: British teen crawled through bus wreckage with a broken back to escape Spain crash that killed 13 students, http://www.mirror.co.uk/news/uk- 
news/british-teen-crawled-through-bus-7599983, (2016).

11. Espinoza, J.: Coach driver killed as bus carrying British schoolchildren crashes in Belgium,

http://www.telegraph.co.uk/news/worldnews/europe/belgium/11704108/One-killed-asbus-carrying-British-schoolchildren-crashes-in-Belgium.html, (2015).

12. Department for Education: Home to school travel and transport guidance: Statutory guidance for local authorities. 1-37 (2014).

13. Ramachandran, M., Sahandi, R., Prakoonwit, S., Khan, W.: Intelligent Safety Transport Framework for Schools: A Review of Route Planning and Tracking Systems. 7, (2016)

14. Van Ristell, J. a., Quddus, M. a., Enoch, M.P., Wang, C., Hardy, P.: Quantifying the impacts of subsidy policies on home-to-school pupil travel by bus in England. Transportation (Amst). 42, 45-69 (2014).

15. NorthamptonshireCountyCouncil: School Transport Policy, http://www.northamptonshire.gov.uk/en/councilservices/EducationandLearning/Parent s/travel/Pages/HtoS.aspx.

16. Trucks, V.: operator compliance, (2013).

17. Clarke, V., Braun, V.: Teaching thematic analysis: Over- coming challenges and developing strategies for effective learning. Psychologist. 26, 120-123 (2013).

18. Braun, V., Clarke, V.: Using thematic analysis in psychology Thematic. Qual. Res. Psychol. 3, 77-101 (2006).

19. VOSA: Rules on Drivers 'Hours and Tachographs: Passenger-carrying vehicles in GB and Europe. (2011).

20. VOSA: Public Service Vehicle Operator Licensing Guide for Operators. (2011).

21. DVSA: Staying legal : PSV driver basics. (2014).

22. IRTE: Wheel Security. (2015).

23. Health and Safety Executive: Driving at work. (2014).

24. Health and Safety Executive: Risk Assessment - A brief guide to controlling risk in the workplace. (2014).

25. Health and Safety Executive: Reporting accidents and incidents at work A brief guide to the Reporting of Injuries, Diseases and Dangerous Occurrences Regulations 2013 (RIDDOR. (2013).

26. Executive, H. and S.: Decide who will help you with your duties. (2013).

27. DVSA: National standard for driving buses and coaches. (2013).

28. DVSA: Guide to maintaining roadworthiness. 54 (2014).

29. DVSA: The safe operator's guide. (2016).

30. IRTE: Roadworthiness: Industry Best Practice for PCV ( Passenger Carrying Vehicles). (2008).

31. DVSA: Careless Torque Costs Lives. (2014).

32. Ramachandran, M., Sahandi, R., Prakoonwit, S., Khan, W.: Mathematical Model for Safety Score Calculation for Validation of Coach Operators in the UK. In: Intelligent Transport Systems - From research and development to the market uptake. Springer (2017). 